\section{POS0918 EVALUATION OF SPINAL RADIOGRAPHIC PROGRESSION IN PATIENTS WITH RADIOGRAPHIC AXIAL SPONDYLOARTHRITIS RECEIVING IXEKIZUMAB THERAPY OVER 2 YEARS}

D. Van der Heijde ${ }^{1}$, M. Østergaard ${ }^{2}$, J. D. Reveille ${ }^{3}$, X. Baraliakos ${ }^{4,5}$ A. Kronbergs ${ }^{6}$, D. Sandoval ${ }^{6}$, X. Li ${ }^{6}$, H. Carlier ${ }^{6}$, D. Adams ${ }^{6}$, W. P. Maksymowych ${ }^{7}$ ${ }^{1}$ Leiden University Medical Centre, Department of Rheumatology, Leiden, Netherlands; ${ }^{2}$ University of Copenhagen, Copenhagen Center for Arthritis Research, Center for Rheumatology and Spine Diseases, Rigshospitalet, Denmark; ${ }^{3}$ University of Texas-McGovern Medical School, Division of Rheumatology and Clinical Immunogenetics, Houston, United States of America; ${ }^{4}$ Ruhr-University Bochum, Bochum, Germany; ${ }^{5}$ Rheumazentrum Ruhrgebiet, Herne, Germany; ${ }^{6}$ Eli Lilly and Company, Indianapolis, United States of America; ${ }^{7}$ University of Alberta, Department of Medicine, Edmonton, Canada

Background: It is important to understand the potential effect long-term therapy with biologics can have on structural changes in the spine among patients with active radiographic axial spondyloarthritis (r-axSpA, ankylosing spondylitis). Objectives: We examined radiographic progression in the spine among patients with active r-axSpA treated with ixekizumab, an IL-17A antagonist, for 2 years, and potential predictors of spinal radiographic progression.

Methods: Patients with active r-axSpA, biologic-naive (COAST-V, NCT02696785) or with prior experience with a maximum of 2 TNF inhibitors (COAST-W NCT02696798), received $80 \mathrm{mg}$ ixekizumab every 2 or 4 weeks for 2 years (108 weeks, of which 56 weeks were the COAST-Y extension study, NCT03129100). Mean change from baseline of modified Stoke Ankylosing Spondylitis Spinal Score (mSASSS) (average score from 2 selected readers, blinded for time order) for patients treated with ixekizumab for 2 years with data at both baseline and year 2 is presented ( $\mathrm{N}=230 ; 54 \%$ of total randomized patients). Non-progression is presented for all patients and subgroups based on TNFi-experience. Predictors were identified in multivariate logistic regression models with stepwise selection criteria of $p$-value $<0.1$. All data are observed.

Results: At baseline, patients $(\mathrm{N}=230)$ were predominately male $(82 \%)$ with an average age of 43 years, mean symptom duration of 16 years, $52 \%$ were TNFi-experienced, mean (SD) ASDAS score was 4.0 (0.7), most were HLA-B27 positive $(87 \%)$ and $40 \%$ had syndesmophytes (identified by both selected readers at the same location). Baseline mSASSS (SD) was 11.0 (16.3) and change from baseline at year 2 of treatment was 0.3 (1.8) (Table 1). The proportion of non-progressors (mSASSS change from baseline <2) over 2 years was $89.6 \%$ (total IXE [all patients]), 90.9\% (biologic-naive) and $88.3 \%$ (TNFi-experienced), and, if defined as mSASSS change from baseline $\leq 0,75.7 \%$ (total IXE [all patients]), $78.2 \%$ (biologic-naive) and 73.3\% (TNFi-experienced) (Table 1). Predictors of structural progression at year 2 (mSASSS change $>0$ ) were age, baseline syndesmophytes, HLA-B27 status and gender (Table 1). Week 52 inflammation in MRI SPARCC spine was also identified as a predictor for structural progression at year 2 in a separate model for patients from COAST-V where MRI measures were available at baseline and Week $52(\mathrm{~N}=109)$.

Conclusion: The majority of patients treated with ixekizumab for 2 years did not show radiographic progression, and the overall mean progression was low. Similar levels of non-progression were observed in biologic-naive patients and patients previously exposed to TNFis. Predictors were generally consistent with previous studies.

Table 1. Spinal radiographic changes for patients with active r-axSpA treated with ixekizumab for 2 years

\begin{tabular}{lccc}
\hline Change in mSASSS at year 2 & $\begin{array}{c}\text { All } \\
\text { patients } \\
\mathbf{N = 2 3 0}\end{array}$ & $\begin{array}{c}\text { aiologic-naive } \\
\mathbf{N = 1 1 0}\end{array}$ & $\begin{array}{c}\text { TNFi- } \\
\text { experienced } \\
\mathbf{N = 1 2 0}\end{array}$ \\
\hline Baseline mSASSS, mean (SD) & $11.0(16.3)$ & $10.1(15.5)$ & $11.7(17.0)$ \\
Change at year 2, mean (SD) & $0.3(1.8)$ & $0.3(2.0)$ & $0.4(1.6)$ \\
Change in total mSASSS <2, $\mathrm{n}(\%)$ & $206(89.6)$ & $100(90.9)$ & $106(88.3)$ \\
Change in total mSASSS $\leq 0, \mathrm{n}(\%)$ & $174(75.7)$ & $86(78.2)$ & $88(73.3)$ \\
Multivariable logistic regression model & & &
\end{tabular}

Prediction for change in total mSASSS $>0$, OR $(95 \% \mathrm{Cl})$, p-value All patients $\mathrm{s}^{\mathrm{a}, \mathrm{b}}$

Age ( $\geq 40$ years vs. $<40$ years)

Baseline syndesmophytes ${ }^{\mathrm{b}}$ (yes vs. no)

Baseline HLA-B27 (positive vs. negative)

Gender (male vs, female)

Baseline ASDAS state (>3.5 vs. [2.1, 3.5])
$\mathrm{N}=228$

$2.97(1.41,6.28) \quad \mathrm{p}=0.004^{\mathrm{c}}$

$2.31(1.18,4.54) \quad p=0.015^{c}$

$3.78(1.04,13.75) \quad p=0.044^{\circ}$

$3.16(1.01,9.86) \quad \mathrm{p}=0.047^{\mathrm{c}}$

$2.26(0.96,5.34) \quad \mathrm{p}=0.063$
${ }^{\mathrm{a} C o m b i n e d ~ i x e k i z u m a b ~ g r o u p ~ o f ~ Q 2 W ~ a n d ~ Q 4 W ~ p a t i e n t s ~ w i t h ~ b a s e l i n e ~ a n d ~ y e a r-2 ~ m S A S S S ~}$ data ${ }^{\mathrm{b}}$ Identified by both selected readers at the same location ( 2 patients were not evaluable by both readers) ${ }^{c} p<0.05$ Abbreviations: $A S D A S=A s s e s s m e n t$ of Disease Activity, $\mathrm{Cl}=$ confidence interval, IXE=ixekizumab, mSASSS=modified Stoke Ankylosing Spondylitis Spinal Score, $\mathrm{OR}=$ odds ratio, Q2W=every 2 weeks, Q4W=every 4 weeks, $\mathrm{SD}=$ standard deviation, TNFi=tumor necrosis factor inhibitor
Disclosure of Interests: Désirée van der Heijde Consultant of: AbbVie, Amgen, Astellas, AstraZeneca, Bayer, BMS, Boehringer Ingelheim, Celgene, Cyxone Daiichi, Eisai, Eli-Lilly, Galapagos, Gilead, Glaxo-Smith-Kline, Janssen, Merck Novartis, Pfizer, Regeneron, Roche, Sanofi, Takeda, UCB Pharma, Employee of: Director of Imaging Rheumatology bv., Mikkel Østergaard Consultant of: AbbVie, BMS, Boehringer-Ingelheim, Eli Lilly and Company, Janssen, Merck Pfizer, Roche, UCB, Celgene, Sanofi, Regeneron, Novartis, Grant/research support from: AbbVie, BMS, Merck, UCB, Celgene, Novartis, John D Reveille Paid instructor for: UCB, Eli Lilly and Company, Consultant of: UCB, Eli Lilly and Company, Pfizer, Novartis, Grant/research support from: Janssen, Eli Lilly and Company, Xenofon Baraliakos Speakers bureau: Abbvie, BMS, Lilly, Janssen, Novartis, MSD, Pfizer, Galapagos, Gilead, UCB, Paid instructor for: Abbvie, BMS Lilly, Janssen, Novartis, MSD, Pfizer, Galapagos, Gilead, UCB, Consultant of: Abbvie, BMS, Lilly, Janssen, Novartis, MSD, Pfizer, Galapagos, Gilead, UCB Andris Kronbergs Shareholder of: Eli Lilly and Company, Employee of: Eli Lilly and Company, David Sandoval Shareholder of: Eli Lilly and Company, Employee of: Eli Lilly and Company, Xiaoqi Li Shareholder of: Eli Lilly and Company, Employee of: Eli Lilly and Company, Hilde Carlier Shareholder of: Eli Lilly and Company, Employee of: Eli Lilly and Company, David Adams Shareholder of: Eli Lilly and Company, Employee of: Eli Lilly and Company, Walter P Maksymowych Speakers bureau: Abbvie, Janssen, Novartis, Pfizer, UCB, Consultant of: Abbvie, Boehringer, BMS, Eli Lilly and Company, Novartis, Pfizer, UCB, Grant/research support from: Abbvie, Novartis, Pfizer

DOI: 10.1136/annrheumdis-2021-eular.1620

\section{POS0919 BIMEKIZUMAB SHOWS SUSTAINED LONG- TERM IMPROVEMENTS IN PATIENT-REPORTED OUTCOMES AND QUALITY OF LIFE IN ANKYLOSING SPONDYLITIS: 3-YEAR RESULTS FROM A PHASE 2B STUDY}

X. Baraliakos ${ }^{1}$, M. Dougados ${ }^{2}$, K. Gaffney ${ }^{3}$, R. Sengupta ${ }^{4}$, M. Magrey $^{5}$, N. De Peyrecave $^{6}$, M. Oortgiesen ${ }^{7}$, T. Vaux ${ }^{8}$, C. Fleurinck ${ }^{6}$, A. Deodhar ${ }^{9} .{ }^{1}$ RuhrUniversity Bochum, Rheumazentrum Ruhrgebiet Herne, Herne, Germany; ${ }^{2}$ Hôpital Cochin, Department of Rheumatology, Paris, France; ${ }^{3}$ Norfolk and Norwich University Hospital NHS Trust, Rheumatology Department, Norwich, United Kingdom; ${ }^{4}$ The Royal National Hospital for Rheumatic Diseases, Department of Rheumatology, Bath, United Kingdom; ${ }^{5}$ Case Western Reserve University, MetroHealth Medical Center, Cleveland, United States of America; ${ }^{6}$ UCB Pharma, N/A, Brussels, Belgium; ${ }^{7}$ UCB Pharma, N/A, Raleigh, United States of America; ${ }^{8}$ UCB Pharma, N/A, Slough, United Kingdom; ${ }^{9}$ Oregon Health \& Science University, Division of Arthritis \& Rheumatic Diseases, Portland, United States of America

Background: Bimekizumab (BKZ), a monoclonal antibody that selectively inhibits interleukin (IL)-17A and IL-17F, has demonstrated clinical efficacy and safety in patients with ankylosing spondylitis (AS) treated over a period up to 96 weeks. ${ }^{1,2}$

Objectives: To report 3-year interim patient-reported outcomes (PROs) in patients with active $A S$ treated with $B K Z$ in a phase $2 b$ dose-ranging study (BE AGILE; NCT02963506) and its open-label extension (OLE; NCT03355573).

Methods: BE AGILE study design has been described previously. ${ }^{1}$ Patients treated with BKZ $160 \mathrm{mg}$ or $320 \mathrm{mg}$ every 4 weeks (Q4W) at Week 48 in BE AGILE were eligible for OLE entry. All OLE patients received BKZ $160 \mathrm{mg}$ Q4W. Outcome measures are reported for the OLE full analysis set (patients who entered the OLE and had $\geq 1$ dose of BKZ and $\geq 1$ valid efficacy variable measurement in the OLE), and include: BASDAI, BASDAI50 responder rate, BASFI, fatigue (BASDAI Q1), morning stiffness (mean of BASDAI Q5+6), total spinal pain (numeric rating scale [NRS]), SF-36 PCS and MCS, and ASQoL. Missing data were imputed using multiple imputation ( $\mathrm{Ml}$; based on the missing at random assumption) for continuous variables and non-responder imputation (NRI) for dichotomous variables.

Results: $262 / 303(86 \%)$ patients randomised at BE AGILE study baseline (BL) completed Week 48 on BKZ $160 \mathrm{mg}$ or $320 \mathrm{mg}$, of whom $255 / 262(97 \%)$ entered the OLE (full analysis set: 254). From baseline to Week 48 in BE AGILE, BKZ-treated patients showed clinically relevant improvements in disease activity (BASDAI, BASDAI50), physical function (BASFI), fatigue, morning stiffness, spinal pain, and quality of life (SF-36 PCS and MCS, ASQoL) (Figure 1). Group-level improvements in all reported continuous efficacy measures exceeded published minimally important difference (MID), minimum clinically important improvement (MCII), and/or minimum clinically important difference (MCID) thresholds (Figure 1). ${ }^{3,4}$ Efficacy in all reported outcome measures was maintained or continued to improve from Week 48 to Week 144 or 156 (Figure 1)

Conclusion: BKZ treatment was associated with sustained and consistent efficacy in patients with active AS over 3 years, including patient-reported disease activity, physical function, fatigue, morning stiffness, spinal pain, and quality of life. 


\section{REFERENCES:}

[1] van der Heijde D. Ann Rheum Dis 2020;79:595-604.

[2] Baraliakos X. Arthritis Rheumatol 2020;72 (suppl 10)

[3] Ogdie A. Arthritis Care Res 2020;72 (S10):47-71.

[4] Maruish ME. User's manual for the SF-36v2 Health Survey (3rd ed). 2011; Lincoln, Rl: QualityMetric Incorporated.

Figure. Patient-reported outcomes over 3 years of BKZ treatment

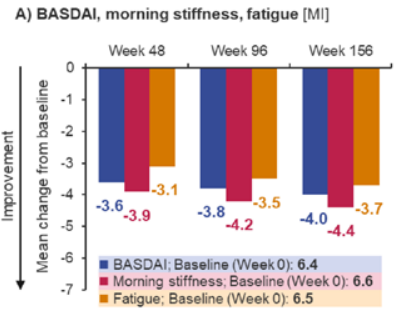

B) BASDAI50 [NRI]

C) BASFI [MI]
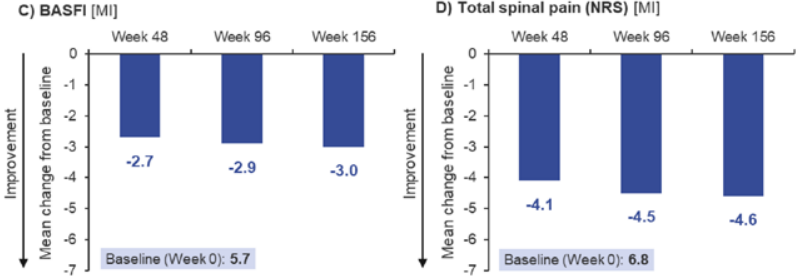

E) SF-36 [MI]

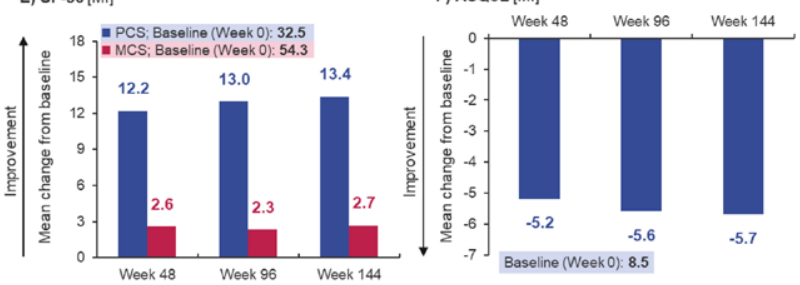

Full analysis set ( $N=254)$. Weeks 0 and 48 refer to the BE AGILE and OLE baseline, respectively. All patients received BKZ $160 \mathrm{~m}$ during the OLE after completing BKZ $160 \mathrm{mg}$ or $320 \mathrm{mg}$ in BE AGILE. SF-36 PCS, MCS and ASQoL were recorded to Week 144 trom baseline represents improvement for all other outcomes. MIDMCIIMCID thresholds: BASDAl total score MCII = 0.7 ; fatigue BASDAI Q1) $\mathrm{MCID}=1.1$; morning stiffness (mean of $\mathrm{BASDAI} Q 5+6) \mathrm{MCID}=1.7$; $B A S F I M C||=0.4$; total spinal pain $\mathrm{MCID}=1.6$ FF-36 PCS score MID $=2$; ASQoL total score MCID $=-2,3$ SF-36 MID values are appropriate for groups with baseline mean -scores of $30-40$, for higher T-score ranges, MID values tend to be higher. ${ }^{-4}$ MID are not applied for improvement for baseline expected. ${ }^{4}$ Since mean SF-36 MCS at baseline was 54.3, the MID was not applied here. ASQoL: Ankylosing Spondylitis Quality of Life questionnaire; BASDAl: Bath Ankylosing Spondyitis Disease Activity Index; BASDAI50: BASDAI 50\% improvement from eline; BASFI: Bath Ankylosing Spondylits Functional Index; BKZ: bimekizumab; MCIll: minimum clinically important ovement; MCID: minimum clinically important difference; MI: multiple imputation; MID: minimally important difference; NR Component Summary, SF-36 PCS: 36--tem Short-Form Survey Physical Component Summary.

Acknowledgements: This study was funded by UCB Pharma. Editorial services were provided by Costello Medical.

Disclosure of Interests: Xenofon Baraliakos Speakers bureau: AbbVie, BMS, Chugai, Eli Lilly, Galapagos, Gilead, MSD, Novartis, Pfizer, UCB Pharma, Paid instructor for: AbbVie, BMS, Chugai, Eli Lilly, Galapagos, Gilead, MSD, Novartis, Pfizer, UCB Pharma, Consultant of: AbbVie, BMS, Chugai, Eli Lilly, Galapagos, Gilead, MSD, Novartis, Pfizer, UCB Pharma, Maxime Dougados Consultant of: AbbVie, Eli Lilly, Novartis, Pfizer and UCB Pharma, Grant/ research support from: AbbVie, Eli Lilly, Novartis, Pfizer and UCB Pharma, Karl Gaffney Speakers bureau: AbbVie, Eli Lilly, Novartis, UCB Pharma, Consultant of: AbbVie, Eli Lilly, Novartis, UCB Pharma, Grant/research support from: AbbVie, Gilead, Eli Lilly, Novartis, UCB Pharma, Raj Sengupta Speakers bureau: AbbVie, Biogen, Celgene, MSD, Novartis, UCB Pharma, Consultant of: AbbVie, Biogen, Celgene, Eli Lilly, MSD, Novartis, UCB Pharma, Grant/ research support from: AbbVie, Celgene, UCB Pharma, Marina Magrey Consultant of: AbbVie, Eli Lilly, Novartis, Pfizer, UCB Pharma, Grant/research support from: AbbVie, UCB Pharma, Natasha de Peyrecave Employee of: UCB Pharma, Marga Oortgiesen Employee of: UCB Pharma, Thomas Vaux Employee of: UCB Pharma, Carmen Fleurinck Employee of: UCB Pharma, Valerie Ciaravino Employee of: UCB Pharma, Atul Deodhar Speakers bureau: Janssen, Novartis, Pfizer, Consultant of: AbbVie, Amgen, BMS, Boehringer Ingelheim, Celgene, Eli Lilly, Gilead, GSK, Janssen, Novartis, Pfizer, UCB Pharma, Grant/research support from: AbbVie, Eli Lilly, GSK, Novartis, Pfizer, UCB Pharma

DOI: 10.1136/annrheumdis-2021-eular.1840

\section{\begin{tabular}{|l|l}
\hline POS0920 & TARGETED SERUM PROTEOMIC ANALYSIS
\end{tabular} FOLLOWING UPADACITINIB TREATMENT IN ANKYLOSING SPONDYLITIS SHOWS ROBUST SUPPRESSION OF INNATE AND ADAPTIVE IMMUNE PATHWAYS WITH TISSUE REPAIR MODULATION}

T. Sornasse ${ }^{1}$, I. H. Song ${ }^{2}$, T. Radstake ${ }^{2}$, D. Mcgonagle ${ }^{3}$. ${ }^{1}$ AbbVie Inc., Immunology Clinical Development, Redwood City, United States of America; ${ }^{2}$ AbbVie Inc., Immunology Clinical Development, North Chicago, United States of America; ${ }^{3}$ University of Leeds, School of Medicine, Leeds, United Kingdom

Background: Upadacitinib (UPA), an oral JAK inhibitor selective for JAK1, demonstrated efficacy in patients with active ankylosing spondylitis (AS) with an inadequate response (IR) to nonsteroidal anti-inflammatory drugs (NSAID) therapy in the SELECT-AXIS $1^{1}$ trial.

Objectives: To identify pathways modulated by UPA in AS patients with emphasis on those associated with response to treatment.

Methods: A subgroup of patients from the SELECT-AXIS 1 study, with available baseline and at least one follow up plasma sample during the placebo-controlled period, were selected for analysis (PBO, $n=65$; UPA $15 \mathrm{mg}$ QD, $n=63$ ). The levels of 92 inflammation related protein biomarkers (BioMs) were analyzed using the Olink $®$ platform; change from baseline were expressed as $\log _{2}$ Fold Change; a repeated measure mixed linear model identified BioMs differentially modulated by UPA. Relationship between change in BioMs and change in clinical disease activity measures were derived using Pearson's correlation (ASDAS-CRP, BASDAI, and CRP) and Spearman's correlation (MRI Spine SPARCC). Pathway analysis was performed with Ingenuity ${ }^{\circledR}$ Pathway Analysis (Qiagen Inc.)

Results: Treatment with UPA $15 \mathrm{mg}$ QD reduced the levels of BioMs associated with IFN, IL6, T Cells, M1 or "inflammatory" Macrophages, and Dendritic Cells (DC); and increased those of BioMs associated with tissue repair and hematopoiesis. The type of pathways, inferred in silico based on BM data, suggests that UPA exerts broad inhibitory activity directly on multiple JAK1-dependent (IFN $\alpha / \beta$, IFN $\gamma$, IL6, IL2, IL5, IL7, and OSM) and indirectly on JAK1-independent upstream pathways (IL1, IL23, IL17, IL18, and TNF $\alpha$ ), resulting in the inhibition of key functional pathways such as leukocyte activation and mobility, inflammatory response, and damage to connective tissue. Improvement in ASDAS-CRP, BASDAI, and MRI spine SPARCC correlated with increase in BioMs associated with tissue repair (FGF5, DNER [Delta/Notch Like EGF Repeat Containing]) and hematopoiesis (FLT3LG, and SCF/KITLG), while improvement in ASDAS-CRP and CRP correlated with decrease in CCL23, CSF1, IL-6, and MMP1; and reduction in only CRP correlated with decrease in IFN- and of TNF $\alpha$-related BioMs (Data tables will be presented).

Conclusion: Treatment of NSAID-IR AS patients with UPA $15 \mathrm{mg}$ QD resulted in the coordinated decrease in multiple BioMs associated with the innate and adaptive immune responses, and in the increase in BioMs generally associated with tissue repair and hematopoiesis. In silico pathway prediction indicates that treatment with UPA directly inhibits JAK1-dependent and indirectly JAK1-independent pathways, resulting in the down modulation of functional pathways related to inflammation and tissue damage which are known to be dysregulated in $A^{2}{ }^{2}$ Based on this observation and on the correlation of change in BioMs with change in clinical measures, we hypothesize that both increase in BioMs associated with tissue repair and hematopoiesis, and decrease in BioMs associated with inflammation may contribute to the clinical activity of UPA in AS patients.

\section{REFERENCES:}

[1] van der Heijde, D. et al. Lancet 394, 2108-2117 (2019).

[2] Stoll, M.L. Clin Exp Rheumatol 29, 322-330 (2011).

Acknowledgements: AbbVie, Inc was the study sponsor, contributed to the study design, data collection, analysis \& interpretation, and to writing, reviewing, and approval of the final version

Disclosure of Interests: Thierry Sornasse Shareholder of: AbbVie, Employee of: AbbVie, In-Ho Song Shareholder of: AbbVie, Employee of: AbbVie, Timothy Radstake Shareholder of: AbbVie, Employee of: AbbVie, Dennis McGonagle Speakers bureau: AbbVie, Grant/research support from: AbbVie DOI: 10.1136/annrheumdis-2021-eular.1894

\section{POS0921 EFFICACY AND SAFETY OF ACEMETACIN IN THE TREATMENT OF 1215 ACTIVE ANKYLOSING SPONDYLITIS PATIENTS: DATA FROM A PROSPECTIVE COHORT MANAGED BY SMART- PHONE SPONDYLOARTHRITIS MANAGEMENT} SYSTEM

J. Zhang ${ }^{1}$, L. Hu ${ }^{1}$, X. Ji ${ }^{1}$, Y. Wang ${ }^{1}$, F. Huang ${ }^{1} .{ }^{1}$ Chinese PLA General Hospital, Rheumatology, Beijing, China

Background: Biological DMARDs have widely used in the treatment of AS in last two decades, but NSAIDs still serves as a cornerstone in the treatment. 